\title{
On force distribution in the staple connections of wood based panels with OSB covers
}

\author{
Anna Al Sabouni-Zawadzka, Wojciech Gilewski ${ }^{*}$,Jan Pełczyński \\ Warsaw University of Technology, Faculty of Civil Engineering, Division of Timber Structures, \\ ul. Lecha Kaczyńskiego 16, 00-637 Warsaw, Poland
}

\begin{abstract}
Prefabricated timber frame structures have been gaining in popularity among the building industry in recent years. The present paper discusses an important aspect of such technologies, which are staple connections of wood based panels with OSB covers. The analysed numerical models indicate a highly non-uniform distribution of forces in staples and show how this phenomenon may be diminished in order to avoid damage of the panels during the transportation and assembly process.
\end{abstract}

\section{Introduction}

Timber frame construction dates back to the $15^{\text {th }}$ and $16^{\text {th }}$ century. A timber frame filled with thermal insulation [1] can be assembled traditionally on the construction site. However, the prefabricated timber frame structures [2,3] have been gaining in popularity in recent years. Such a technology assumes that the wall and floor panels are prefabricated under the full quality control [4] and then they are assembled on the site. There are several big companies in the building industry, which use different prefabrication systems and technologies. The outer layers of the panels are usually made of OSB plates (or similar) which are connected to the timber frame. Production of such panels in a factory requires automation and therefore, the staple connections are commonly used [5]. Ready panels of different lengths and weights are transported both within the factory and on the construction site with the use of cranes. This leads to large concentrated loads applied to the upper beams of the panels. Moreover, the loaded areas of the beams are additionally weakened by notches and discontinuities in the staples' rows, which are necessary for suspending the panels. Damage of the panels can occur due to the withdrawal of the staples from the OSB cover or destruction of the material around them. In such cases, a non-uniform distribution of forces in staples should be expected, which depends on their spacing and possible loss.

Observation of the panels damaged during the transportation process justifies the need for developing numerical models, which would allow to determine forces in staples and to assess the risk of the staple withdrawal or pulling it through the OSB plate. Such models were developed for the purpose of this paper. A parametric analysis of the modelled

\footnotetext{
* Corresponding author: w.gilewski@il.pw.edu.pl
} 
suspended panel was performed. The calculations were conducted using the finite element method.

\section{Computational model and results}

\subsection{Finite element model}

Numerical models for the parametric analysis were built using the finite element method [6] with the Abaqus software [7]. The models represent the real properties of the panels. The analysed panel consists of beams and columns which are not connected with one another. These elements create a frame that is connected with an OSB plate using staples. The load is transferred through OSB covers and staples to the upper beam, which is suspended on ropes - in the suspension areas the cross-section of the beam is weakened due to notches. The staples are modelled as points, in which the displacements of beams, columns and plates are equal. The contact area of OSB plates and beams/columns is modelled as a one side contact problem [7] - pressing the OSB plates against the beams generates contact, pulling them off does not. Apart from the contact issue, the problem is modelled as linear elastic. The following averaging isotropic parameters for timber $\mathrm{C} 24$ were adopted: mean density: $420 \mathrm{~kg} / \mathrm{m}^{3}$, Young's modulus: $11 \mathrm{GPa}$, Poisson's ratio: 0.25. The OSB parameters were adopted for the transverse isotropy [8-10]: mean density: $550 \mathrm{~kg} / \mathrm{m}^{3}$, Young's moduli: $\mathrm{E}_{1}=\mathrm{E}_{2}=3.5 \mathrm{GPa}, \mathrm{E}_{3}=1.4 \mathrm{GPa}$, Poisson's ratios: $v_{12}=0.2, v_{13}=v_{23}=0.1$, Kirchhoff's moduli: $\mathrm{G}_{12}=1.458 \mathrm{GPa}, \mathrm{G}_{13}=\mathrm{G}_{23}=0.583 \mathrm{GPa}$. Three types of finite elements were considered: 8node solid elements (24 degrees of freedom with linear shape functions), 20-node solid elements (60 degrees of freedom with quadratic shape functions) and 8-node shell elements (48 degrees of freedom). The best convergence, with the smallest number of elements, was achieved for the 20-node solid elements and thus, such elements were used in all further calculations. In the chosen finite elements a reduced integration is used.

\subsection{Panel 1- wooden frame with OSB covers}

Model no. 1 is a panel $60 \mathrm{~cm} \times 100 \mathrm{~cm}$ that is suspended on one rope. The numerical model presented in Fig. 1 consists of 11986 finite elements and has 87462 degrees of freedom.

a)

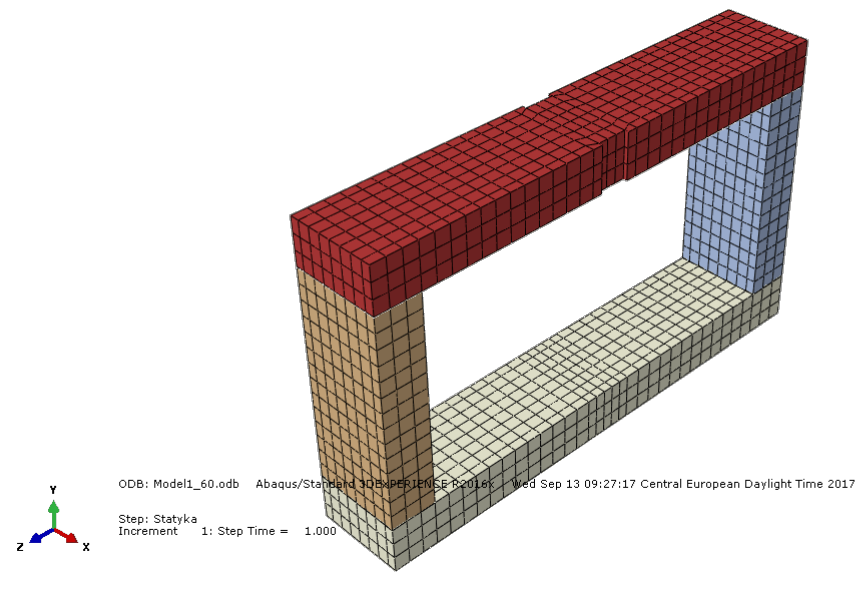


b)

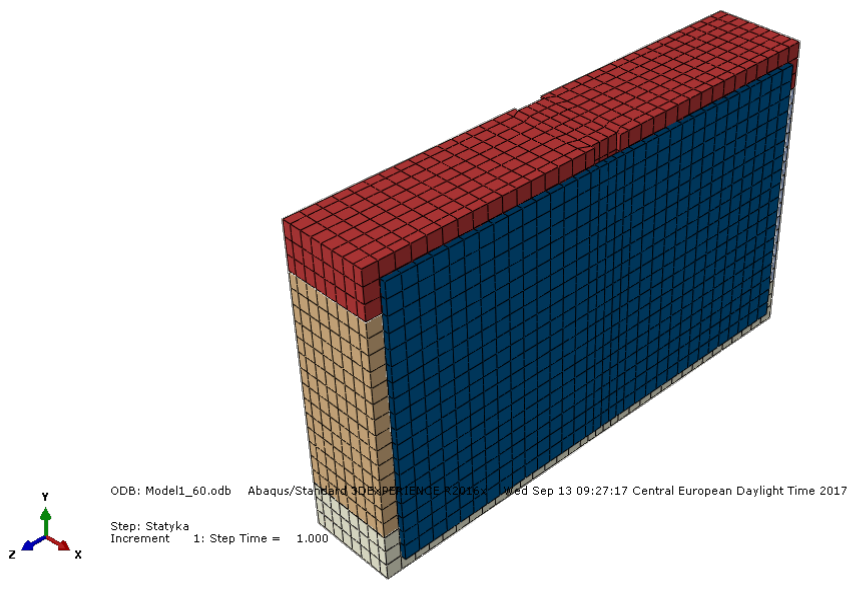

Fig. 1. Computational model 1: timber frame (a) and frame with OSB covers (b).

The analyses were performed for several cases of spacing and location of staples. In the basic model a spacing of $60 \mathrm{~mm}$ was adopted, the staples were applied circumferentially apart from the area of the notch for the suspension of the upper beam. Moreover, a spacing of $120 \mathrm{~mm}$ along the upper beam was considered and three cases of staples loss around the suspension zone were taken into account. The following parameters were analysed: distributions of displacements of the panel and stress in the upper beam and the OSB covers, distributions of normal and vertical forces in staples. Synthesised results of the performed analyses are presented in Tab. 1 and Fig. 2 and 3.

Table 1. Model 1 - selection of results.

\begin{tabular}{|l|c|c|c|c|c|}
\hline \multirow{2}{*}{$\begin{array}{l}\text { Load } \\
2426 \mathrm{~kg}\end{array}$} & $\begin{array}{c}\text { Max stress } \\
\text { in the } \\
\text { beam } \\
{[\mathrm{MPa}]}\end{array}$ & $\begin{array}{c}\text { Max } \\
\text { displacement } \\
\text { of the beam } \\
{[\mathrm{mm}]}\end{array}$ & $\begin{array}{c}\text { Max } \\
\text { displacement } \\
\text { of the cover } \\
{[\mathrm{mm}]}\end{array}$ & $\begin{array}{c}\text { Normal } \\
{[\mathrm{N}]}\end{array}$ & $\begin{array}{c}\text { Vertical } \\
{[\mathrm{N}]}\end{array}$ \\
\hline $\begin{array}{l}\text { Staples } \\
\text { every } \\
60 \mathrm{~mm}\end{array}$ & 6.068 & 0.448 & 1.110 & 641.8 & 2503 \\
\hline $\begin{array}{l}\text { Loss of } \\
\text { staples A }\end{array}$ & 7.755 & 0.609 & 1.113 & 781.0 & 3198 \\
\hline $\begin{array}{l}\text { Loss of } \\
\text { staples A } \\
\text { and B }\end{array}$ & 9.701 & 0.879 & 1.051 & 917.1 & 3954 \\
\hline $\begin{array}{l}\text { Loss of } \\
\text { staples C } \\
\text { (or further }\end{array}$ & 6.048 & 0.470 & 1.133 & 701.7 & 2704 \\
\hline $\begin{array}{l}\text { Staples } \\
\text { every } \\
\text { 120mm }\end{array}$ & 6.160 & 0.505 & 1.175 & 864.4 & 3390 \\
\hline
\end{tabular}

Staples A, B, C, ... numbered successively from the suspension towards the ends of the beam. 
Distributions of normal stress along the grain of the upper beam (in the cross-sections lying in the axis of the upper surface of the beam) and distributions of vertical displacements of the upper surface of this beam differ slightly from the corresponding distributions obtained from the beam models. The displacement curve is not parabolic - it "straightens" and then slightly "bends upwards" as it moves away from the suspension. The displacements of the panel are very small because the OSB covers stiffen the upper beam.

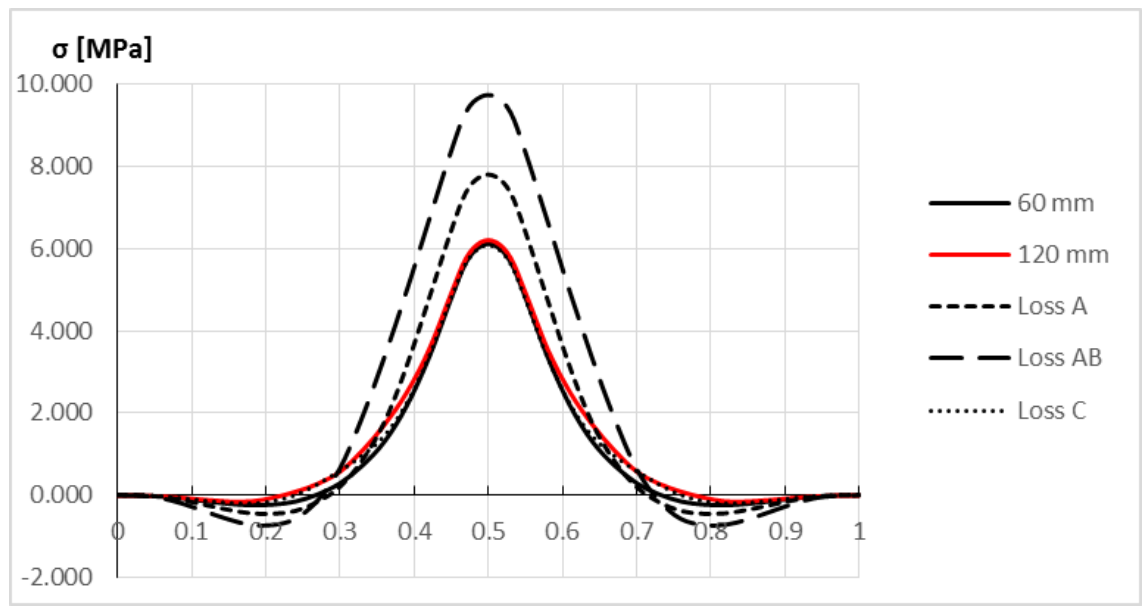

Fig. 2. Distribution of normal stress in the grain direction on upper surface of upper beam - Model 1.

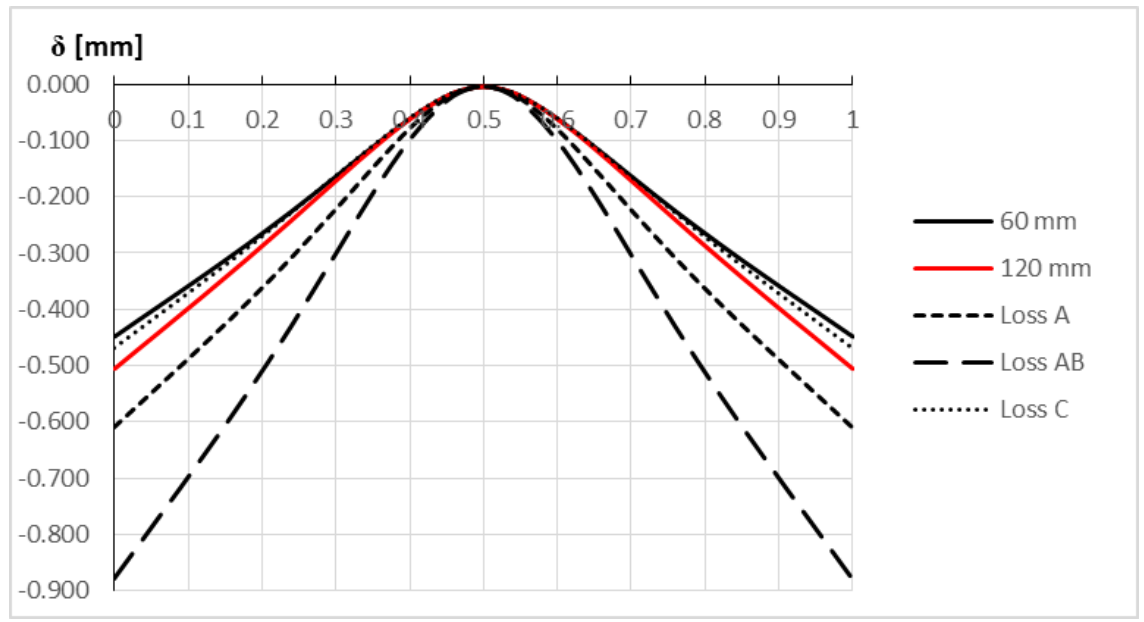

Fig. 3. Distribution of vertical displacements of upper beam - Model 1.

All staples with spacing $60 \mathrm{~mm}$.

Normal stresses along the grain of the upper beam are significantly lower than the limiting values. Vertical displacements of the upper beam and horizontal displacements of the OSB plates are very little. Apart from the suspension zone in the upper beam, the panel behaves like a rigid solid.

Fig. 4 presents deformation of the panel in the considered model. A characteristic feature of this deformation are displacements of the OSB plates towards the inside of the panel. In the same time, the part of the plate that lies above the staples on the upper beam 
deflects outwards. Such a deformation pattern explains the damage process of the panels that were subjected to experimental testing.

a)

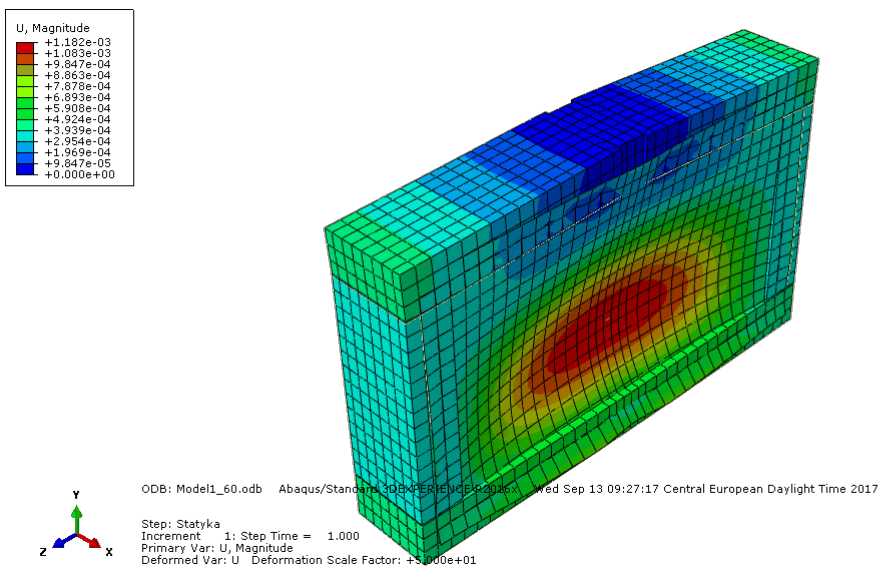

b)

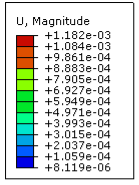

Fig. 4. Maps of horizontal displacements: full panel (a) and half of panel (b) - Model 1.

The values of forces in staples located in the upper beam are presented in Fig. 5. The staples were numbered consecutively at both sides of the panel - this is why some longer horizontal lines can be noticed in the diagrams. Distributions of forces in staples are nonuniform. The biggest vertical force is almost three times bigger than the arithmetic mean of the non-uniform distribution. The damage of the connection occurs as a result of simultaneous work of withdrawing and shear forces and the particular features of OSB plates which have a mostly random layout of the laminas in the outer layer.

Loss of staples.

Loss of staples A as well as A and B generates bigger stresses, which however still do not reach the limiting values. Loss of further staples (C) influences slightly only the maximum forces in the remaining staples. The displacements in all cases remain unchanged.

All staples with spacing $120 \mathrm{~mm}$.

Stresses and displacements remain almost unchanged. Forces in staples increase significantly. 
a)

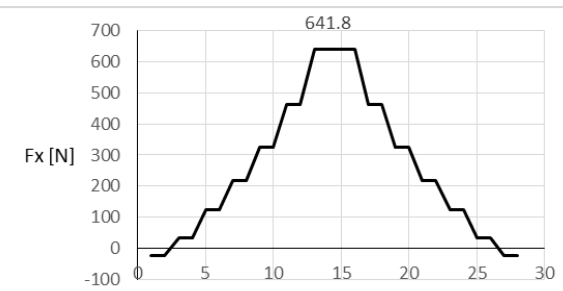

b)

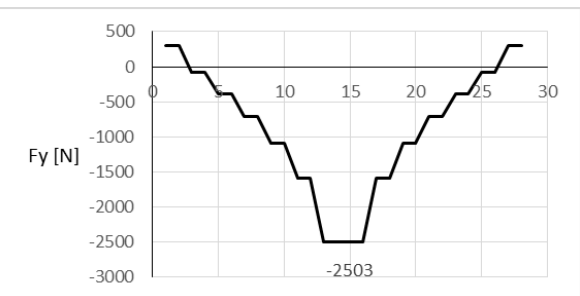

Fig. 5. Distribution of withdrawal forces (a) and shear forces (b) in staples - Model 1.

\subsection{Panel 2 - stiffened wooden frame with OSB covers}

The numerical model is presented in Fig. 6. Number of finite elements 13502. Number of degrees of freedom 99144.

In Model no. 2 the panel was supplemented with two columns inside the frame in order to check, even in such a small panel with the width of $100 \mathrm{~cm}$, how the presence of such columns affects the results of the analysis.

a)

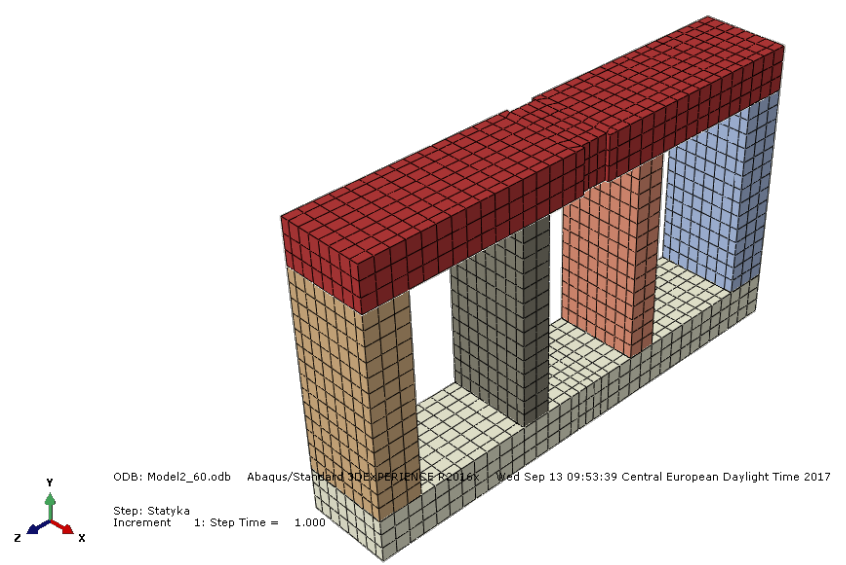

b)

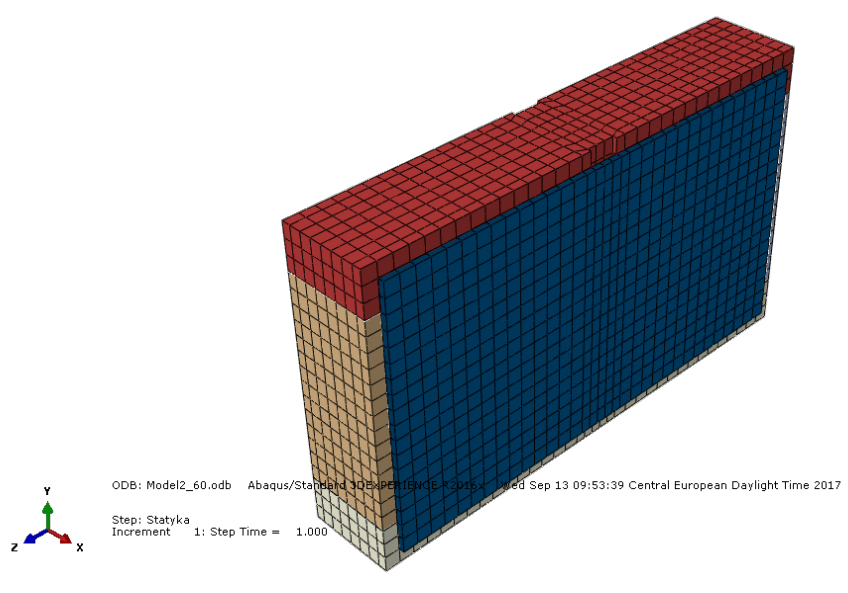

Fig. 6. Computational model 2: timber frame (a) and frame with OSB covers (b).

Synthesised results are presented in Tab.2. 
Table 2. Model 2 - selection of results.

\begin{tabular}{|l|c|c|c|c|c|}
\hline \multirow{2}{*}{$\begin{array}{l}\text { Load } \\
\text { kg } \\
\mathrm{kg}\end{array}$} & $\begin{array}{c}\text { Max stress } \\
\text { in the beam } \\
{[\mathrm{MPa}]}\end{array}$ & $\begin{array}{c}\text { Extreme values } \\
\text { displacement of } \\
\text { the beam } \\
{[\mathrm{mm}]}\end{array}$ & $\begin{array}{c}\text { Max } \\
\text { displacement of } \\
\text { the cover } \\
{[\mathrm{mm}]}\end{array}$ & $\begin{array}{c}\text { Normal } \\
{[\mathrm{N}]}\end{array}$ & $\begin{array}{c}\text { Vertical } \\
{[\mathrm{N}]}\end{array}$ \\
\hline $\begin{array}{l}\text { Staples } \\
\text { every } \\
60 \mathrm{~mm}\end{array}$ & 5.843 & 0.411 & 0.115 & 532.4 & 2515 \\
\hline $\begin{array}{l}\text { Loss of } \\
\text { staples A }\end{array}$ & 7.510 & 0.567 & 0.081 & 660.5 & 3332 \\
\hline $\begin{array}{l}\text { Loss of } \\
\text { staples A } \\
\text { and B }\end{array}$ & 9.524 & 0.845 & 0.121 & 787.5 & 4079 \\
\hline $\begin{array}{l}\text { Loss of } \\
\text { staples C } \\
\text { (or further }\end{array}$ & 5.821 & 0.432 & 0.115 & 581.4 & 2715 \\
\hline $\begin{array}{l}\text { Staples } \\
\text { every } \\
\text { 120mm }\end{array}$ & 5.951 & 0.471 & 0.115 & 698.6 & 3444 \\
\hline
\end{tabular}

Adding the columns resulted in ca. $17 \%$ decrease of normal forces in staples, with the vertical forces remaining unchanged. The values of normal stress along the grain insignificantly decreased, the displacements remained very small. The obtained results indicate a significant increase of the load-carrying capacity of the staples, which means that the additional columns work in favour of the whole system.

Deformation of Model no. 2 is presented in Fig. 7. It can be noticed that the displacements of the OSB covers differ significantly from the previous model. However, in the area near the suspension the plate deflects towards the inside of the panel and it bends locally outwards over the staples' line, which suggests a damage scenario similar to Model no. 1.

a)

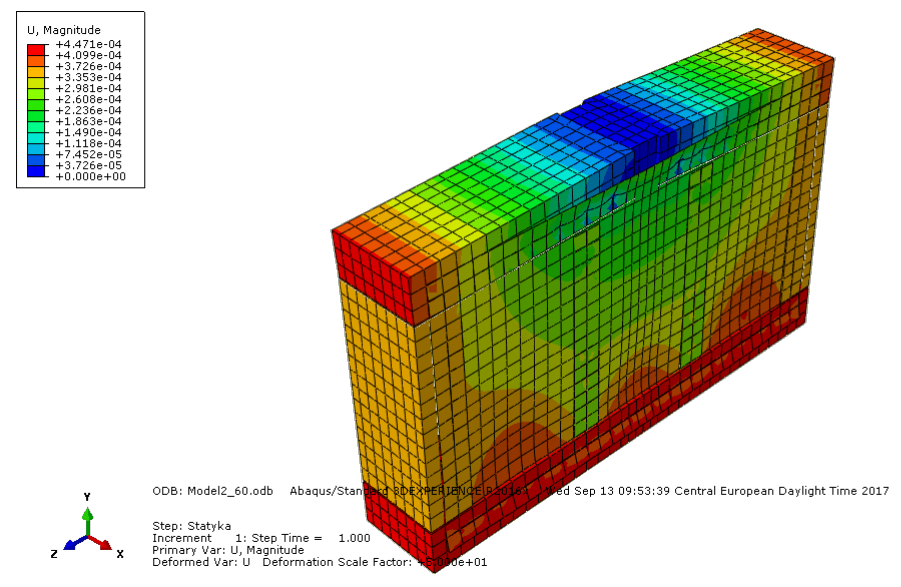




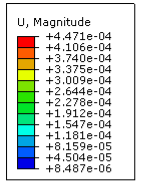

b)

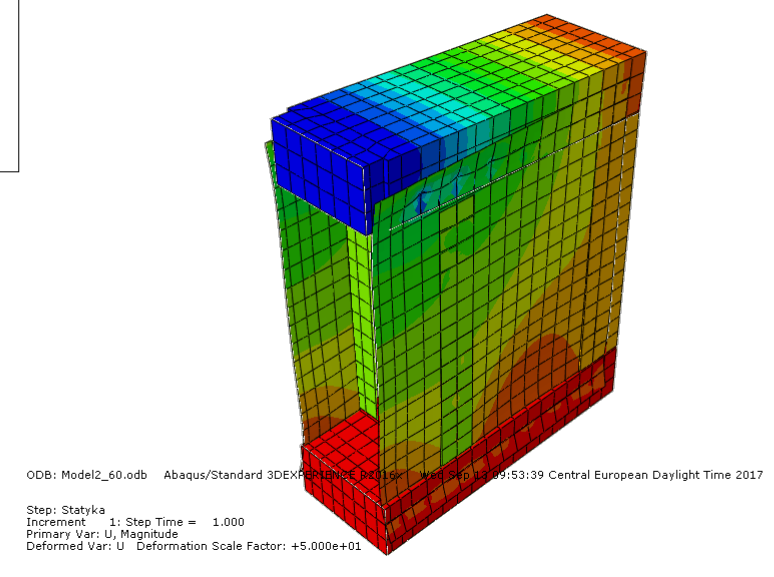

Fig. 7. Maps of horizontal displacements: full panel (a) and half of panel (b) - Model 2.

\section{Conclusions}

In the present paper a numerical analysis of a panel that consists of a timber frame covered with two OSB plates is presented. The OSB plates are connected with the frame with the use of staples. A strongly non-uniform distribution of withdrawal and shear forces in staples is to be observed, which generates a potential risk of panels damage during the transportation or assembly process. Application of the inner intermediate columns reduces the displacements of the OSB covers and improves safety of the structure. Loss of staples near the suspension areas is not safe and should be avoided. In the light of the presented results the production precision and quality control in the factory takes on special significance.

\section{References}

1. A. Węglarz, P. Gilewski, Procedia Eng., 153, pp. 862-865, (2016)

2. A. Kermani, Proc. Inst. Civil Eng., Structures \& Buildings, 159, pp.13-19, (2006)

3. J. Zhou, M. Zaki Hassan, Z. Guan, W. J. Cantwell, Compos. Sci. Technol., 72, pp. 1781-1790, (2012)

4. A. Węglarz, P. G. Gilewski, MATEC Web of Conf., 117, pp.1-7, (2017)

5. R. Lancashire, L. Taylor, Timber frame construction, TRADA Tech. Ltd., 5th Edition, (2011)

6. O.C. Zienkiewicz, R.L. Taylor, The finite element method. Vol. 1. The basis. Butterworth-Heinemann, New Jersey, (2000)

7. ABAQUS Documentation, (2017)

8. E.C. Zhu, Z.W. Guan, P.D. Rodd, D.J. Pope, Holz. Roh. Werkst, 63, pp. 87-93 (2005)

9. V. Sebera, L. Muszyński, Holzforschung, 65, pp. 811-818, (2011)

10. E.C. Zhu, Z.W. Guan, P.D. Rodd, D.J. Pope, Advances in Engineering Software, 36, pp. 797-805, (2005) 